\title{
Enumeration of CD34+ blasts by immunohistochemistry in bone marrow biopsies from MDS patients may have significant impact on final WHO classification
}

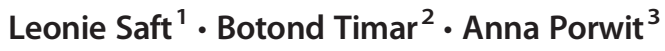 \\ Received: 20 February 2020 / Accepted: 1 April 2020 / Published online: 23 April 2020 \\ (C) The Author(s) 2020
}

\begin{abstract}
The percentage of blasts cells in the bone marrow (BM) of MDS patients is one of the key parameters for MDS classification and for the differential diagnosis with acute myeloid leukemia (AML). Currently, the gold standard to determine the blast percentage is conventional cytomorphology. To assess the possible impact of blast cell enumeration in BM biopsies from MDS patients on the final WHO classification using CD34 immunohistochemistry (IHC) a total of 156 BM samples from MDS and MDS-AML patients were studied and compared to blast counts by cytomorphology (CM). Eighty-nine BM aspirates were also studied by flow cytometry (FCM). Percentages of CD34+ blasts by IHC were determined blindly by two hematopathologists. Automated CD34-cell count was performed in 25 cases. Good overall agreement was found for CM and FCM with respect to critical blast thresholds $(5 \%, 10 \%, 20 \%)(p<0.05)$. However, in $17 \%$ of patients, CD34+ blast counts by IHC were higher as compared to CM with possible impact on MDS subclassification. In 7 of 21 AML patients, diagnosis was established on BM histology, while the blast percentage by CM was below the AML threshold. The assessment of CD34+ cells by IHC showed high interobserver agreement (Spearman R 0.95, $p<0.01$ ), while automated CD34 counts were not optimal due to interference with other cellular and stromal elements. BM histology including CD34 IHC improves the diagnostic accuracy in MDS and AML. The quantification of blast cells should be based on the integration of all three methods for reliable disease classification and risk assessment.
\end{abstract}

Keywords Bone marrow biopsy $\cdot$ CD34 immunohistochemistry $\cdot$ Cytomorphology $\cdot$ Blast percentage $\cdot$ Flow cytometry

\section{Introduction}

The cytomorphological enumeration of blast percentages in bone marrow (BM) smears is a critical parameter for classification of myelodysplastic syndromes (MDSs) [1]. The blast

Electronic supplementary material The online version of this article (https://doi.org/10.1007/s12308-020-00394-9) contains supplementary material, which is available to authorized users.

Leonie Saft

leonie.saft@sll.se

1 Department of Clinical Pathology, Division of Hematopathology, Karolinska University Hospital and Institute, Solna, Stockholm, Sweden

2 1st Department of Pathology and Experimental Cancer Research, Semmelweis University, Budapest, Hungary

3 Department of Clinical Sciences, Division of Oncology and Pathology, Faculty of Medicine, Lund University, Lund, Sweden percentage is also an important prognostic marker as reflected by the high intrinsic prognostic power of the WHO classification [2]. Blast percentage cut-offs at 5\%,10\%, 20\%, and 30\% are included as prognostic factors in the International Prognostic Scoring System (IPSS) [3]. The further splitting of the lower blast range into two separate groups $(0-2 \%$ vs $>2-<5 \%$ ) in the revised IPSS (R-IPSS) provided groups with very low risk versus low-risk features [4]. Indeed, patients with $\leq 2 \%$ BM blasts had lower risk of disease progression into acute myeloid leukemia (AML) and a more favorable outcome [4].

The International Working Group on Morphology of MDS proposed a consensus for the definition and enumeration of BM blasts, widely implemented in clinical practice [5]. Although the reliability of blast cell count with respect to the $5 \%$ threshold has been demonstrated [6-8], the reproducibility of counts within the lower blast range has been questioned. Font et al. found low agreement among cytologists when analyzing MDS patients with $\leq 2 \% \mathrm{BM}$ blast counts [6]. 
Therefore, even when good-quality BM smears are available, the reproducible identification and quantification of blast cells might be a challenge. Moreover, blast counts in smears may not be representative due to hemodilution or low cellularity of smears that are often seen in hypoplastic MDS or in MDS with significant ( $\geq$ grade 2 WHO) fibrosis [9-12]. In addition, CD34+ cell clusters as identified by immunohistochemistry (IHC) that were reported as independent prognostic marker for progression to AML may be seen even in MDS without blast excess by cytomorphology (CM) [13, 14]. In follow-up samples from MDS patients under treatment, BM topography may be severely altered with variation in cellularity and residual focal increase of blasts. Therefore, according to European Leukemia Network (ELN) guidelines and the revised WHO classification of MDS, the blast percentage by conventional $\mathrm{CM}$ should always be correlated to BM histology including IHC staining for CD34 $[15,16]$.

Multiparameter flow cytometry (FCM) is an important complementary tool for the analysis of the blast compartment in MDS. Previous studies have shown a strong correlation between FCM and CM with regard to blast enumeration [17-19]. Among other criteria, enumeration of CD34+ cells by FCM has been evaluated, but it proved to be considerably lower than morphological blast cell counts in a significant number of cases [20-24]. However, it has been shown that a $2 \%$ cut-off for CD34+ cells by FCM reached higher prognostic significance than $2 \%$ blasts by CM [25]. A recent multicenter quality assurance study stressed the need for a standardized approach for the enumeration of CD34+ myeloid blast cell count by FCM [26]. A series of publications from the International MDS Flow Cytometry Working and the ELN group provided guidelines for FCM application in the diagnostic work-up of MDS [23, 27-31]. However, as it has been stated in the revised WHO 2017, FCM results cannot replace the morphological differential count in the MDS subclassification [1,32].

A number of previous studies compared the percentages of blasts by CM to the assessment of the blast compartment by FCM. In this study, we assessed the percentage of CD34+ blasts by IHC in BM biopsies from MDS patients and compared the results to the blast counts obtained by conventional $\mathrm{CM}$ and, in a subset of patients, also to the enumeration of CD34+ myeloid blast cells by FCM. By using three different methods in a simultaneous setting, we demonstrate that BM histology with CD34 IHC identifies a significant number of patients with higher blast counts than found by $\mathrm{CM}$ and FCM. Importantly, diagnostically relevant differences in blast percentages were more often detected in trephine biopsies as compared to clots from aspirates, strongly supporting the use of the former at initial investigation for correct disease classification.

\section{Methods}

\section{Study design}

This retrospective study was performed using archived BM samples (BM trephines/clots from aspirates together with $\geq 2$ BM smears and $\geq 1$ imprint from BM trephines) from patients with MDS $(n=135)$ and AML with myelodysplasia-related changes $(n=21)$, obtained at initial diagnosis (between 2004 and 2016). Material for FCM was available in 89 of 135 (66\%) MDS patients. BM trephines from AML patients were referred from outside hospitals without material for FCM. All samples were reviewed and reclassified by two experienced hematopathologists (LS, AP) according to the WHO 2017 classification [16]. Baseline characteristics of the study cohort are shown in Table 1 (detailed data is provided in Supplemental Tables 1-2). This study was performed in line with the principles of the Helsinki Declaration. Approval was granted by the Swedish Ethical Review Authority (Dnr 200900394).

\section{Bone marrow histology and cytomorphology}

CD34 IHC staining (mouse MoAb CD34 QBend10, RTU) was performed on FFPE BM sections using a Ventana BenchMark automated slide stainer. The fraction of CD34positive blast cells was assessed in randomly selected fields based on a count of $\geq 500$ hematopoietic cells using $\times 60$ lens and $\mathrm{a} \times 10$ eyepiece. A CD34+ cluster was defined as a group of $\geq 3$ positive cells as previously described [13]. BM cellularity and grade of marrow fibrosis (MF) according to European consensus guidelines [33] were documented for each case. Automated quantification of CD34+ cells was performed in 25 BM samples (Pannoramic ${ }^{\text {TM }}$ P250 digital slide scanner, 3DHISTECH Ltd., Budapest, Hungary) to compare results with manual counting and to evaluate whether this technique is feasible in the routine clinical setting.

BM smears and imprints stained with May-GrunwaldGiemsa at time of initial diagnosis were all reassessed and the percentage of blasts was calculated according to WHO guidelines [1]. Morphological features used for the definition of myeloblasts were those proposed by the International Working Group on Morphology of MDS [5].

\section{Multiparameter flow cytometry}

The $\mathrm{BM}$ aspirates were processed within $2 \mathrm{~h}$ from sampling using a stain and lyse/wash technique [34]. Data acquisition was performed using FACS Calibur (BD) flow cytometer (4color panel) and FACS Canto II (BD) (8-color panel) for samples collected between 2004 and 2007 and 2008 and 2016, respectively. The applied panels are shown in Supplementary Tables 3-4. The percentage of myeloid $\mathrm{CD} 34^{+}$cells was 
Table 1 Baseline characteristics of the study cohort

\begin{tabular}{|c|c|c|}
\hline & $\begin{array}{l}\text { MDS }(n=135) \\
\text { No. }(\%)\end{array}$ & $\begin{array}{l}\text { AML with myelodysplasia related changes }(n=21) \\
\text { No. }(\%)\end{array}$ \\
\hline Median age, years (range) & $71(2-89)$ & $73(52-83)$ \\
\hline Sex, male/female & $77 / 58$ & $11 / 10$ \\
\hline \multicolumn{3}{|l|}{ WHO 2017} \\
\hline $\begin{array}{l}\cdot \text { MDS del5q } \\
\text { - MDS-RS-MLD } \\
\cdot \text { MDS-SLD } \\
\text { - MDS-MLD } \\
\text { - MDS-EB } \\
\text { o MDS-EB-1 } \\
\text { o MDS-EB2 } \\
\text { - Refractory cytopenia of childhood (RCC) } \\
\text { BM biopsy, specimen type }\end{array}$ & $\begin{array}{l}6(4 \%) \\
7(5 \%) \\
3(2 \%) \\
64(47 \%) \\
52(39 \%) \\
33(24 \%) \\
19(14 \%) \\
3(2 \%)\end{array}$ & \\
\hline $\begin{array}{l}\text { - BM trephine } \\
\text { - Aspiration biopsy }\end{array}$ & $\begin{array}{l}96(71 \%) \\
39(28 \%)\end{array}$ & $\begin{array}{l}21 \\
0\end{array}$ \\
\hline Cellularity, median (range) & $64 \%(20-100 \%)$ & $68 \%$ (range $10-100 \%$ ) \\
\hline \multicolumn{3}{|l|}{ Marrow fibrosis } \\
\hline $\begin{array}{l}\text { - Grade } 0-1 \\
\text { - Grade } 2-3\end{array}$ & $\begin{array}{l}115(85 \%) \\
20(15 \%)\end{array}$ & $\begin{array}{l}18(97 \%) \\
3(15 \%)\end{array}$ \\
\hline \multicolumn{3}{|l|}{ CD34+ clusters } \\
\hline - Present & $30(22 \%)$ & $N A$ \\
\hline \multicolumn{3}{|l|}{ IPSS-R cytogenetic risk group } \\
\hline $\begin{array}{l}\text { - Very good/good } \\
\text { - Intermediate } \\
\text { - Poor/very poor } \\
\text { - Missing data }\end{array}$ & $\begin{array}{l}64(47 \%) \\
13(10 \%) \\
52(39 \%) \\
6(4 \%)\end{array}$ & $\begin{array}{l}1(5 \%) \\
1(5 \%) \\
17(80 \%) \\
2(10 \%)\end{array}$ \\
\hline
\end{tabular}

$M D S-R S-M L D$ MDS with ring sideroblasts and multilineage dysplasia, $M D S-S L D$ MDS with single lineage dysplasia, $M D S-M L D$ MDS with multilineage dysplasia, $M D S-E B$ MDS with excess blasts, $N A$ not applicable

calculated from all nucleated BM cells after excluding debris and doublets. In the 4-color panel, CD34+ B cell precursors were excluded as CD34+ cells with very low SSC [24]. In the 8-color panel, CD34+ myeloid blast cells were identified by the $\mathrm{CD} 45^{\mathrm{dim}} \mathrm{CD} 34^{+} \mathrm{CD} 117^{+} \mathrm{CD} 19^{-}$(tube 1 ) and $\mathrm{CD} 45^{\mathrm{dim}}$ $\mathrm{CD} 34^{+} \mathrm{CD} 117^{+} \mathrm{CD} 33^{+} 13^{\text {dim }}$ HLA-DR $^{+}$phenotype (tube 2 ). Following ELN guidelines [30], aberrant myeloid blast populations were identified by loss or overexpression of myeloidassociated antigens, aberrant expression of lymphoid markers, and monocytic differentiation by the expression of CD11b, CD64, and CD36.

\section{Statistical analyses}

The Spearman rank correlation coefficient and Pearson test (two-sided) were used to determine the correlation between blast cell percentages as assessed by the three methods. The chi-square and Fisher's exact tests were used to assess the correlation between concordant and discordant cases with respect to the IPSS cytogenetic subgroup. The non-parametric Mann Whitney test was used to assess the effect of marrow fibrosis on blast percentage for the comparison between $\mathrm{CM}$ and IHC. All $p$ values are two-tailed and considered statistically significant when $<0.05$. The statistical analyses were performed using Statview (Abacus Concepts Inc., Berkeley, CA, USA).

\section{Results}

\section{Baseline clinical and morphological characteristics}

Of 135 MDS cases, most were either MDS-MLD (47\%) or MDS-EB (39\%), while other subtypes were less frequent (Table 1). In 129 patients with available data, the distribution of IPSS-R cytogenetic risk groups was as follows: very good/ good $(n=64)$, intermediate $(n=13)$, and poor/very poor $(n=$ 52). Among AML with myelodysplasia-related changes (AML-MRC), 17 of 19 patients with available data had poor or very poor cytogenetics including del $(5 q)$ with complex karyotypes in 15 patients. BM showed median cellularity of $64 \%$ and $68 \%$ (range 10-100\%) in MDS and AML patients, respectively; 14 of 135 (10\%) MDS and 3 of 21 (14\%) AML patients had $\leq 30 \%$ BM cellularity. Moderate or severe $(\geq$ grade 2) marrow fibrosis was seen in $15 \%$ of samples in both groups. The majority of the specimen from MDS patients 
were BM trephines (96 of 135 cases). All AML patients had adequate BM trephines, while BM aspirate for FCM was not available for this group.

\section{Characteristics of CD34 immunostaining and interobserver reproducibility}

BM trephines $(n=117)$ and clots from aspirates $(n=39)$ were retrospectively reviewed by two experienced hematopathologists (LS and AP) in a blinded fashion for the percentage of CD34+ cells. The individual results of CD34 IHC in MDS and AML-MRC patients are provided in Suppl. Tables 1-2. CD34-IHC showed $\geq 1 \%$ cells consistent with blasts in 89 of $135(66 \%)$ MDS; all AML-MRC cases were CD34-positive. Uneven distribution of CD34-positive blast cells and CD34-positive clusters were frequently seen in MDS-EB subtypes (25 of 53 cases, 47\%) and occasionally in MDS-MLD (5 of 63 cases, 8\%) (Fig. 1). Of note, four of MDS-MLD cases $(<5 \%$ blasts by $\mathrm{CM}$ ) had also an overall increase of CD34-blasts cells by IHC (>5\%). In addition, strong aberrant CD34 expression in megakaryocytes was frequently observed, particularly in MDS-EB subtypes as illustrated in Fig. 2.

The blinded assessment of CD34+ blast cells by both reviewers in a subset $(n=26)$ of patients ( 7 MDS-MLD, 14 MDS-EB-1/2, 5 AML) showed high interobserver correlation (Suppl. Figure 1, Spearman R 0.95, $p<0.01$ ). Notably, both reviewers found higher percentage of CD34+ blast cells by IHC as compared to CM with respect to WHO blast thresholds in 7 of $21(33 \%)$ MDS cases, many of which showed uneven distribution of CD34-positive blast cells in the BM biopsies. The five AML cases were diagnosed on the basis of BM histology and CD34 IHC while blast percentages by CM were below the AML threshold.

\section{Comparison of the blast count by cytomorphology to the percentage of CD34-positive blast cells by immunohistochemistry and flow cytometry}

Based on the blast count performed on BM smears and imprints in comparison to the percentage of CD34+ cells by either IHC or FCM, the cases were stratified into three groups according to WHO blast thresholds. Of 132 cases, 84 (64\%) cases had $<5 \%, 30(23 \%)$ between $\geq 5$ and $<10 \%$, and 18 $(13 \%)$ between $\geq 10$ and $19 \%$ BM blasts by CM. BM smears/ imprints were inadequate (hemodiluted) in three cases, all had an increase of CD34+ blasts by IHC (Suppl Table 1, cases no. 103,107 , and 133) and two had grade 2 marrow fibrosis. Among 14 MDS cases with lower cellularity $(\leq 30 \%)$ and $<$ $5 \%$ blasts by CM, IHC detected an increase of CD34+ blast cells in 2 cases (cases no. 85, 91). Seven other cases with < $20 \%$ blasts by CM were classified as AML-MRC on the basis of histopathological findings.

\section{Comparison of $\mathrm{CM}$ blast count and the percentage of CD34-positive blast cells in BM histology}

When comparing the two techniques, 95 of 132 (72\%) cases were within the same blast range (Table 2). However, the results were not significantly correlated (Suppl. Figure 2, Pearson's $\mathrm{r} 0,728, p=0.113$ for groups). BM histology revealed a higher percentage of CD34+ blasts in 23 of 132 (17\%) samples (with CD34+ clusters in four patients) as compared to CM, which would allocate the patients to a higher WHO MDS subgroup and a higher IPSS-R prognostic blast score value. Only two of these samples had $\geq$ grade 2 marrow fibrosis. Based on the IHC results, 12 patients with $<5 \% \mathrm{BM}$ blasts by CM (all MDS-MLD) would be moved to the MDSEB category, and 11 patients with 5-9\% blasts by CM (MDSEB1) would be reclassified as MDS-EB2. Higher percentages of CD34+ blast cells in BM histology as compared to the CM blast counts were more often detected in BM trephines as compared to aspirate clots $(P<0.05)$, reflecting that uneven distribution of blast cells may be more easily detected in BM trephines than in clots. In this series, the blast frequency and classification were not affected by the presence or absence of marrow fibrosis. In contrast, higher blast percentages by $\mathrm{CM}$ as compared to the percentage of CD34 by IHC and/or FCM with respect to classification thresholds were seen in 14 of 132 MDS (10\%), which may indicate that not all blasts were CD34 positive. Among those, the presence of aberrant blast populations truly negative for both CD34 and CD117 was confirmed in two of nine cases with available material for FCM. Among samples with $<1 \%$ CD34-positive blast cells by IHC $(n=46)$, only four cases had an increase of blasts by CM (between 7 and $11 \%$ ). Of those four cases, two had $\leq 1 \%$ and one $1 \%$ CD34+ myeloid blasts by FCM; the fourth was not diagnostic due to hemodilution.

\section{Comparison of CM blast count and the percentage of CD34+ myeloid blasts by FCM}

The blast count in BM smears/imprints and the percentage of CD34+ myeloid blasts by FCM were within the same range in 78 of 88 cases $(88 \%)$ with respect to the critical WHO blast thresholds. The results of the measurements are summarized in Table 3 and illustrated in Suppl. Figure 3 (Pearson's r 0.782 , $p<0.01$ for both groups and absolute values). The percentage of blasts by CM vs FCM was higher in 10 (11\%) cases, ranging between 6 and $12 \%$ of total BM cells. Direct comparison to FCM results showed $<5 \%$ CD34+ myeloid blasts in all but one of these cases (with similar results for IHC), of which four had $\leq 1 \%$ CD34+ myeloid blasts, indicating that blast cells were negative for this marker. A higher percentage of CD34+ myeloid blasts by FCM vs CM was seen in one case ( $9 \%$ vs 3\%, respectively); the histological material consisted 
a

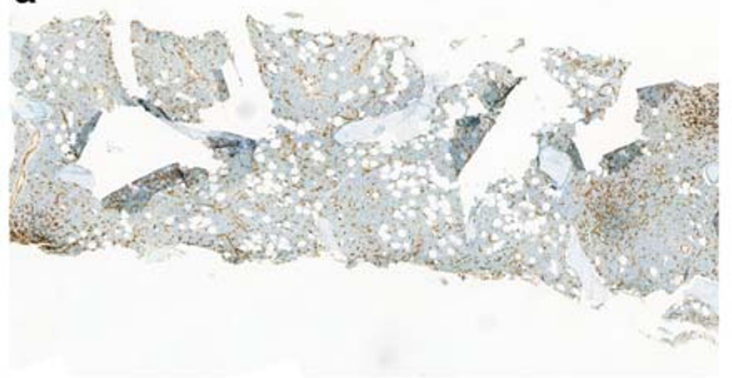

C

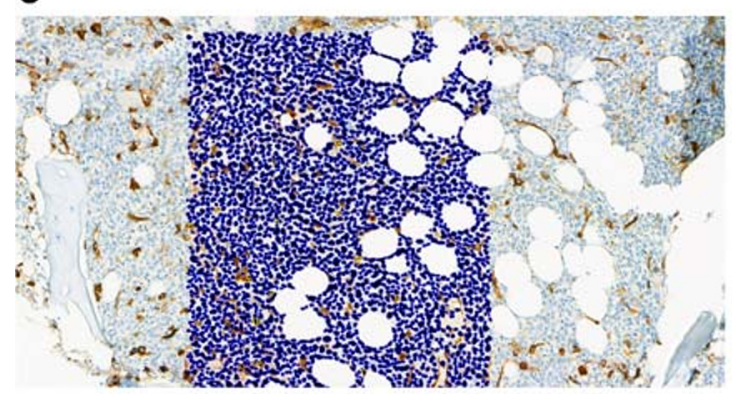

b

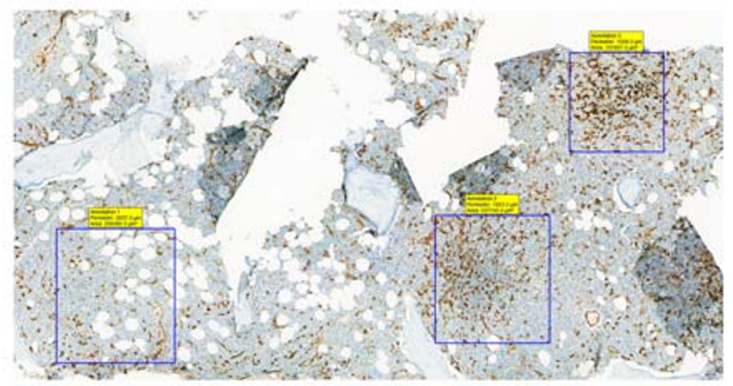

d

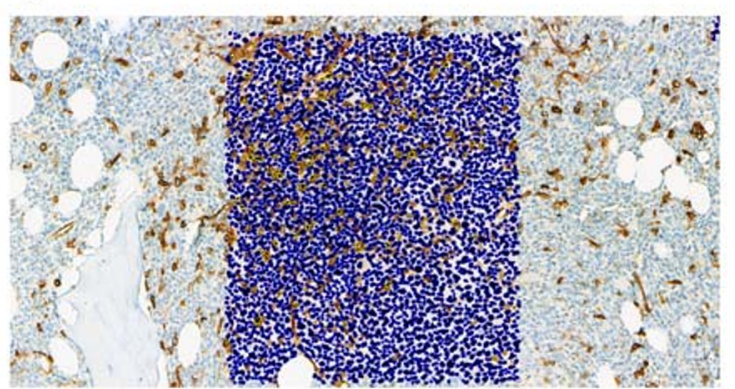

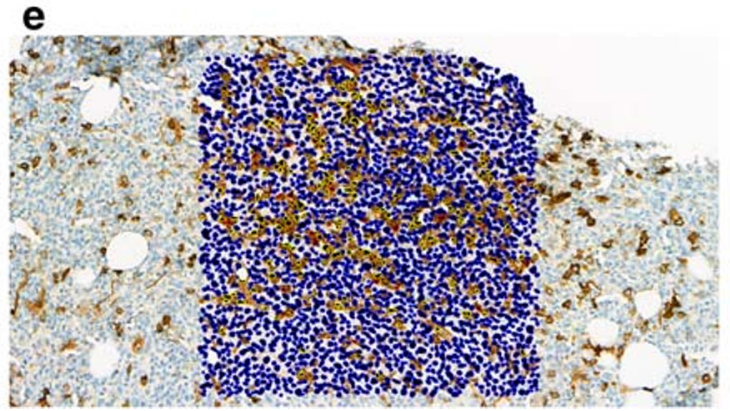

Fig. 1 a-e BM trephine with uneven distribution of CD34+ blast cells in a patient with MDS-MLD and poor-risk cytogenetics (case 110). Images are shown in $\times 4, \times 6.7, \times 30$, and $\times 37$ magnification. The automated

of a BM clot with $30 \%$ cellularity and $<1 \%$ CD $34+$ IHC cells without evidence of fibrosis.

\section{Comparison of the percentage of CD34 blasts by immunohistochemistry and FCM}

The two methods showed results within the same blast range in 75 of 89 (84\%) cases: 68 of $89(76 \%)$ samples had $<5 \%, 2$ cases between $\geq 5$ and $<10 \%$, and 5 cases between $\geq 10$ and $19 \%$ by both methods (Table 4 and Suppl. Figure 4, Pearson's r $0.767, p 0.012$ for blast groups). Differences in the percentages of CD34-positive blasts $(n=14)$ were mainly due to higher values in the BM trephines, likely explained by uneven distribution of blast cells and the presence of CD34-positive clusters. In three cases, the CD34+ blast percentage was higher by FCM with similar results for blast percentage in BM smears. Notably, the corresponding biopsy material was BM aspirate clots with high cellularity in two cases $(80 \%$ and count in the three annotation areas (b) measured $1.25 \%(\mathbf{c}), 4.5 \%$ (d), and $14 \%$ (e) CD34-positive cells

$90 \%$ ) and low cellularity (30\%) in one case. The findings may indicate that BM biopsies, in particular BM trephines, detect higher blast percentages in a fraction of cases that may be more difficult to detect in BM aspirate clots. The percentage of normal early B-cell precursors (by FCM) was $<0.1 \%$ in all MDS with $\geq 5 \% \mathrm{CD} 34+$ blasts by IHC and available material for FCM; an example for this is shown in Suppl. Figure 5.

\section{Higher blast percentages in bone marrow histology in comparison to cytomorphology is associated with shorter overall survival and poor-risk cytogenetics}

Data on follow-up time, time to progression and overall survival (OS) were collected for all MDS patients. To study the impact of higher blast counts in BM biopsies on OS, MDSMLD and MDS-EB patients were assessed separately (Suppl. Figure 6a-b). Patients with MDS-MLD and $\geq 5 \%$ CD34+ 
a

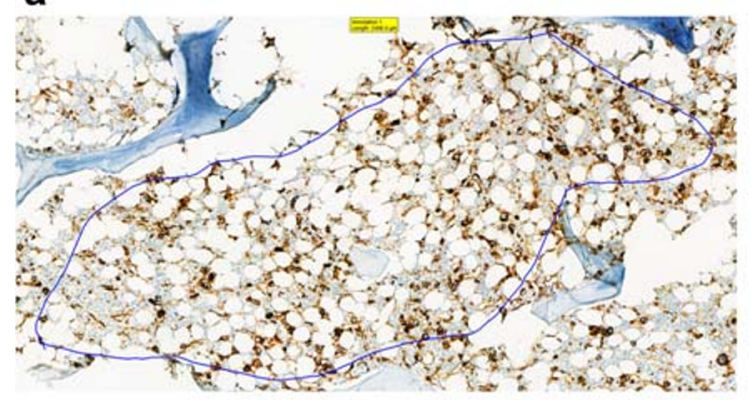

C

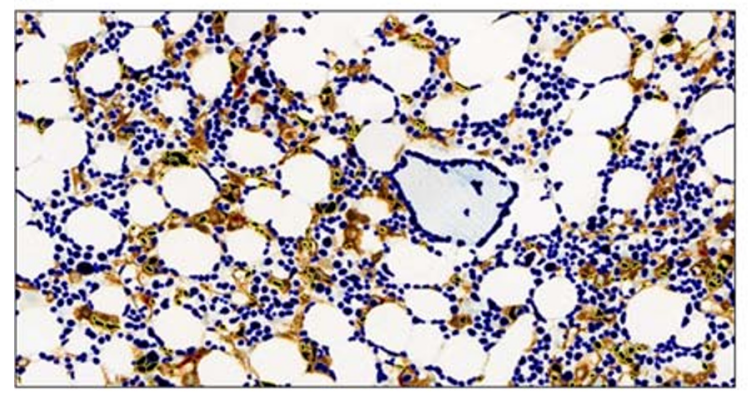

b

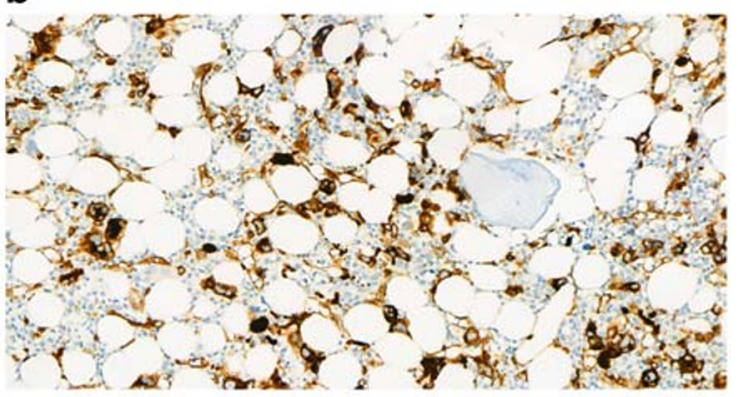

d

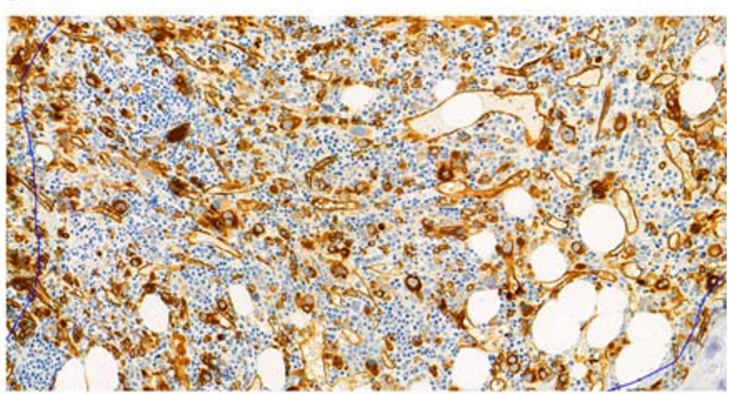

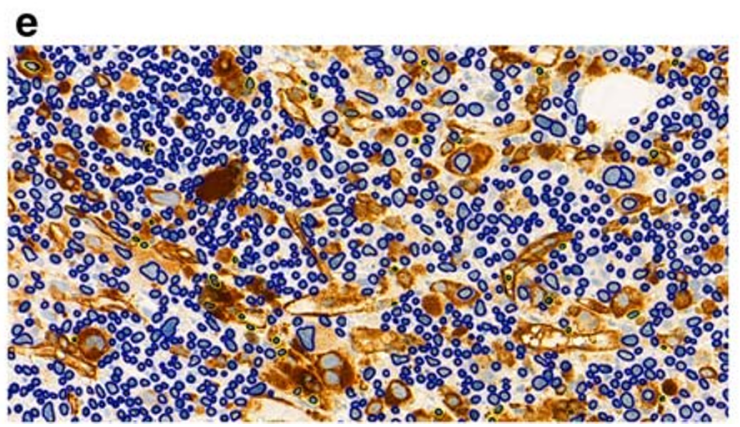

Fig. 2 a-e Automated count of CD34-positive structures. The color markers (yellow, orange, red) indicate different chromogen staining intensities on structures with nuclei detectable by the counterstain. Micromegakaryocytes with strong aberrant expression of CD34 were frequently counted "positive" (case no. 100, a-c). By using individual

blasts by IHC $(n=12)$ had shorter OS as compared to MDSMLD with $<5 \%$ by both methods $(n=59)$; OS at 2 years was $10 \%$ and $55 \%$ for the two groups, respectively $(p<0.0001$,

Table 2 Comparison of blast percentage by CM and CD34 IHC in BM biopsies

\begin{tabular}{lcccc}
\hline \multicolumn{4}{c}{ Percentage of CD34+ cells by IHC } & \\
\cline { 2 - 4 } & $<5 \%$ & $\geq 5-<10 \%$ & $\geq 10<20 \%$ & Total \\
\hline BM blasts $\%$ & & & \\
$<5 \%$ & $72(55 \%)$ & $9(7 \%)$ & $3(2 \%)$ & $84(64 \%)$ \\
$\geq 5-<10 \%$ & $9(7 \%)$ & $10(8 \%)$ & $11(8 \%)$ & $30(23 \%)$ \\
$\geq 10<20 \%$ & $3(2 \%)$ & $2(2 \%)$ & $13(10 \%)$ & $18(14 \%)$ \\
Total & $84(64 \%)$ & $21(16 \%)$ & $27(21 \%)$ & $132(100 \%)$ \\
\hline
\end{tabular}

measurement settings and defining morphological characteristics of blast cells (e.g., cell size/shape and nuclear size), non-blast cells could be excluded. However, in some cases, CD34+ blast cells were not recognized due to a weak nuclear counterstain (case $80, \mathbf{d}, \mathbf{e}$ )

log-rank). However, 9 of 12 (75\%) had poor/very poor IPSS cytogenetics as compared to 12 of 59 (20\%) MDS-MLD

Table 3 Comparison of blast percentage by $\mathrm{CM}$ and the percentage of CD34+ myeloid blasts by FCM

\begin{tabular}{lcccl}
\hline \multicolumn{4}{c}{ Percentage of CD34+ cells by FCM } & \\
\cline { 2 - 3 } & $<5 \%$ & $\geq 5-<10 \%$ & $\geq 10<20 \%$ & Total \\
\hline BM blasts $\%$ & & & \\
$<5 \%$ & $64(73 \%)$ & $1(1 \%)$ & $0(0 \%)$ & $65(74 \%)$ \\
$\geq 5<10 \%$ & $7(8 \%)$ & $8(9 \%)$ & $0(0 \%)$ & $15(17 \%)$ \\
$\geq 10<20 \%$ & $1(1 \%)$ & $1(1 \%)$ & $6(7 \%)$ & $8(9 \%)$ \\
Total & $72(82 \%)$ & $10(11 \%)$ & $6(7 \%)$ & $88^{\mathrm{a}}(100 \%)$ \\
\hline a 89 cases had a bone marrow aspirate for FCM assessment; BM smears \\
were not diagnostic in one case due to hemodilution
\end{tabular}


Table 4 Comparison of the percentage of CD34+ blasts by IHC and FCM

\begin{tabular}{lccll}
\hline & \multicolumn{2}{l}{ CD34-positive myeloid blasts by FCM } & \\
\cline { 2 - 4 } IHC CD34\% & $<5 \%$ & $\geq 5-<10 \%$ & $\geq 10-<20 \%$ & Total \\
\hline$<5 \%$ & $68(76 \%)$ & $2(2 \%)$ & $0(0 \%)$ & $70(79 \%)$ \\
$\geq 5-<10 \%$ & $3(3 \%)$ & $2(2 \%)$ & $1(1 \%)$ & $6(7 \%)$ \\
$\geq 10-20 \%$ & $2(2 \%)$ & $6(7 \%)$ & $5(6 \%)$ & $13(15 \%)$ \\
Total no (\%) & $73(82 \%)$ & $10(11 \%)$ & $6(7 \%)$ & $89(100 \%)$ \\
\hline
\end{tabular}

patients ( $p=0.001$, chi-square test). MDS progression was documented in 1 of 12 and 10 of 59 MDS-MLD patients; mean last morphological follow-up time was 41 months. For MDS-EB1 patients $(n=33)$ with blast percentages in the same range $(\geq 5-9 \%)$ for both methods $(n=22)$ or higher by CD34 IHC $(n=11)$, OS at 2 years was $30 \%$ and $18 \%$, respectively $(p=0.78, \log$-rank); 14 of $22(63 \%)$ and 6 of $11(54 \%)$ had poor/very poor IPSS-R cytogenetics $(p=0.975$, chi-square test). Disease progression and/or AML transformation was documented in 10 of $52(19 \%)$ MDS-EB1/2 patients, and two of these had higher $(\geq 10 \%)$ blast counts by BM histology vs CM; mean last morphological follow-up time was 17 months.

Cytogenetic data with respect to the whole cohort was available in 129 MDS patients (Suppl. Table 1); three of these cases had inadequate cytomorphological material. For the purpose of statistical analysis, patients were grouped into very $\operatorname{good} / \operatorname{good}(n=63)$, intermediate $(n=13)$, and poor/very poor $(n=50)$ cytogenetic risk groups according to the revised International Prognostic Scoring System (R-IPSS). Differences in blast percentages affecting critical classification thresholds were highly associated with poor-risk cytogenetic abnormalities; 15 of 22 patients with higher blast counts in BM histology vs CM had poor or very poor cytogenetics (for example case 110, shown in Fig. 1), while 7 patients had good or intermediate cytogenetics $(p=0.026)$.

\section{AML with multilineage dysplasia}

In seven of 21 AML patients, diagnosis was established by BM histology (CD34+ blast infiltration $\geq 20 \%$ ) with lower blast counts by CM. Six of these patients had grade 2 BM fibrosis. In one patient with hypoplastic AML, the blast percentage could not be assessed due to extremely hypocellular smears. Among nine AML patients with $\geq 20-<30 \%$ blasts by $\mathrm{CM}$, the percentage of CD34+ cells by IHC exceeded $30 \%$ in three patients. This is an important clinical observation, since some clinical trials use the $30 \%$ threshold as criterion for exclusion. The blast count was higher in smears in one AML sample, indicating that not all blast cells were CD34+ positive.

\section{Automated quantification of CD34+ blast cells in bone marrow biopsies}

BM slides were scanned using a Pannoramic ${ }^{\mathrm{TM}}$ P250 Flash digital slide scanner (3DHISTECH Ltd., Budapest, Hungary) equipped with a CIS color camera (CIS Corporation, Tokyo, Japan) for bright field image acquisition. Automated quantification of CD34+ cells was performed in 25 cases using the Case Viewer 2.3.0 software with QuantCenter 2.2.1 plug-in (3DHISTECH Ltd. Budapest, Hungary) using CellQuant (CQ) application for image analysis. The measurement was performed in predefined, randomly selected annotation areas rather than whole-image analysis, hereby excluding extramedullary tissue, trabecular bone, "empty spaces," and subcortical areas (Fig. 2). Endothelial cells served as internal control for CD34-positivity. In spite of individual measurement settings for defining characteristics of CD34+ blast cells (including cell size, nuclear shape, staining intensity) in each of the selected BM samples, non-blast cells (e.g., hyperplastic, non-flattened endothelial cells or micromegakaryocytes with strong aberrant CD34 expression) and unspecific structures (e.g. non-cellular background staining) were frequently counted as "CD34-positive." This error could not be completely eliminated, but calibration of the CQ with the adjustable parameters (color deconvolution for the nuclear counterstain, cell/nucleus size, and size of the cytoplasm) helped to reduce counting of non-blast cells. After these calibrations, the results of the automated count were in some cases comparable to the manual count (Suppl. Table 6). Taken altogether, automated quantification of CD34+ blast cells in BM biopsies is currently still problematic for routine clinical use due to technical pitfalls but also due to the cellular heterogeneity and unspecific or aberrant immunoreactivity in various BM compartments.

\section{Discussion}

Enumeration of blast cells in the BM of MDS patients is a key parameter for correct assignment to MDS subgroups, as well as for the differential diagnosis between MDS and AML. In addition, it is used as a single independent prognostic marker in currently available prognostic risk scores $[4,35]$. In the updated WHO guidelines [1], despite inaccuracies inherent in manual differential counting, conventional CM is still considered the gold standard to determine blast counts.

Previous studies have shown a generally good correlation between CM and FCM for BM blast enumeration [17, 19], but it has been shown that FCM may underestimate or overestimate blast cell counts in individual cases. The percentage of CD34+ myeloid cells by FCM has been tested as a substitute for a CM count; however, blasts in MDS may not express CD34 [36, 37]. Other studies have shown that the CD34 ${ }^{\text {high }}$ and/or CD $117^{+} \mathrm{HLA}-\mathrm{DR}^{+}$phenotype of total events showed the highest degree of correlation and agreement with the 
morphological assessment of blast counts [19]. However, BM samples taken in a simultaneous setting for cytomorphology and FCM analysis, respectively, may differ in terms of cellularity and blood contamination. FCM has not been accepted as a complementary tool for BM blast count in routine clinical practice but provides valuable information on blast immunophenotype and maturation patterns of various BM cell lineages. In our series, we observed good overall concordance between $\mathrm{CM}$ and FCM with respect to critical blast thresholds (88\% of cases). In four of 53 MDS with excess blasts $(\geq 5 \%$ by $\mathrm{CM}$ ), the percentage of $\mathrm{CD} 34+$ myeloid blasts by FCM was $\leq 1 \%$ indicating that blast cells lacked this marker.

According to recommendations from the ELN and the revised WHO 2017 diagnostic guidelines, BM trephines should be performed in all patients with suspected MDS for whom BM examination is indicated $[15,16]$. Immunohistochemical analysis with CD34 is especially useful for assessing blast percentage in MDS with fibrosis or a hypocellular bone marrow, in which blast percentages are often underestimated. Moreover, it allows the enumeration of CD34+ blast cells and identification of CD34+ cell clusters, which were found to have an independent impact on both overall survival and leukemia-free survival [13]. Previous studies in MDS and AML have shown that CD34 IHC increases diagnostic accuracy [38]. Dunphy et al. found that IHC detected higher CD34+ blast counts as compared to the blast count obtained in smears, which resulted in a change of the initial classification [38]. It has also been illustrated that during follow-up of treated AML patients with CD34+ myeloid blast cells at initial diagnosis, IHC detected higher blast counts ( $>5 \%)$ as compared to $\mathrm{CM}(<5 \%)$ in a number of cases [39]. Other studies have proven high overall concordance for positive and negative results for CD34 by IHC in comparison to either CM or FCM [40, 41]. Correlation with FCM may particularly be helpful in MDS cases with micromegakaryocytic hyperplasia and strong aberrant CD34 expression. We demonstrate here a high interobserver correlation for the blinded morphological assessment of CD34+ blasts cells in BM biopsies and good overall concordance between IHC and FCM with respect to critical blast thresholds. However, BM histology detected higher blast percentages by IHC as compared to CM in $17 \%$ of MDS cases, which would allocate patients to a higher subcategory and IPSS risk group. Discrepant cases were seen in both MDS-MLD and MDS-EB subtypes and associated with shorter overall survival and poorrisk cytogenetics. In seven of 21 AML patients, final diagnosis was established on the basis of histology and IHC, while cytomorphology of the smears did not fulfill the criteria for leukemia diagnosis. Importantly, discordant cases were more frequently detected in BM trephines as compared to clots from aspirates. Differences in blast percentages between $\mathrm{CM}$ and BM histology may partly be explained by uneven distribution of CD34+ blast cells and the presence of CD34+ clusters, which are more easily detected in a trephine biopsy and more frequently seen in high-risk MDS.
The automated assessment of CD34 in BM biopsies was found problematic due to technical issues and positive staining in different cellular and stromal compartments. In addition, the distribution and frequency of CD34-positive blast cells can vary within samples which may require an individual approach for the automated count including the selection of adequate annotation areas and the definition of negative and positive scores (e.g., size of blast cells).

In summary, our findings illustrate that $\mathrm{CM}$ does not establish correct blast counts in $100 \%$ of cases and should be used with the awareness that BM histology may reveal higher blast percentages, particularly in MDS with high-risk features. Accordingly, as the most reasonable and reliable approach to diagnosing and classifying MDS, we propose the combination of all three methods as gold standard for the assessment of marrow blasts. This should be applied in a simultaneous setting and as part of an integrative diagnostic approach for correct assignment of patients to specific risk categories and MDS subgroups. In cases with increased blast percentages in BM histology, final MDS classification should be based on the higher blast count even if the percentage of blasts by $\mathrm{CM}$ is below the $5 \%$ threshold. The CM blast count cannot be replaced by FCM, but if FCM finds significant higher counts in the BM aspirate, control sampling may be considered. To our knowledge, there are no larger published studies who have analyzed the percentage of blast cells in BM samples from MDS patients by all three methods (CM, FCM, and BM histology together with IHC) in a simultaneous setting. Additional studies to define standards for the enumeration of CD34 cells in BM samples are currently ongoing by members of the European Bone Marrow Working Group [42]. The findings of our study will be followed up in a larger, populationbased cohort of MDS patients at initial diagnosis and under treatment with correlation to clinical data and survival.

Acknowledgments The authors thank the staff at the Department of Clinical Pathology, Hematopathology Laboratory, Karolinska University Hospital, Solna, for preparation of bone marrow samples for morphological and flow cytometric analysis.

Author contributions All the authors contributed to the study conception and design. Material preparation and data collection was performed by Leonie Saft. Data analysis was performed by all three authors (LS, BT, and AP). The first draft of the manuscript was written by Leonie Saft, and all the authors commented on previous versions of the manuscript. All the authors read and approved the final manuscript.

Funding Information Open Access funding provided by Karolinska Institute.

\section{Compliance with ethical standards}

Conflict of interest The authors declare that they have no conflict of interest. 
Ethical approval This study was performed in line with the principles of the Helsinki Declaration. Approval was granted by the Swedish Ethical Review Authority (Dnr 2009-00394).

Open Access This article is licensed under a Creative Commons Attribution 4.0 International License, which permits use, sharing, adaptation, distribution and reproduction in any medium or format, as long as you give appropriate credit to the original author(s) and the source, provide a link to the Creative Commons licence, and indicate if changes were made. The images or other third party material in this article are included in the article's Creative Commons licence, unless indicated otherwise in a credit line to the material. If material is not included in the article's Creative Commons licence and your intended use is not permitted by statutory regulation or exceeds the permitted use, you will need to obtain permission directly from the copyright holder. To view a copy of this licence, visit http://creativecommons.org/licenses/by/4.0/.

\section{References}

1. Swerdlow SH, World Health Organization, International Agency for Research on Cancer (2017) WHO classification of tumours of haematopoietic and lymphoid tissues. World Health Organization classification of tumours, Revised 4th edition. edn.

2. Cazzola M, Malcovati L (2010) Prognostic classification and risk assessment in myelodysplastic syndromes. Hematol Oncol Clin North Am 24(2):459-468

3. Greenberg P, Cox C, LeBeau MM, Fenaux P, Morel P, Sanz G, Sanz M, Vallespi T, Hamblin T, Oscier D, Ohyashiki K, Toyama K, Aul C, Mufti G, Bennett J (1997) International scoring system for evaluating prognosis in myelodysplastic syndromes. Blood 89(6):2079-2088

4. Greenberg PL, Tuechler H, Schanz J, Sanz G, Garcia-Manero G, Sole F, Bennett JM, Bowen D, Fenaux P, Dreyfus F, Kantarjian H, Kuendgen A, Levis A, Malcovati L, Cazzola M, Cermak J, Fonatsch C, Le Beau MM, Slovak ML, Krieger O, Luebbert M, Maciejewski J, Magalhaes SM, Miyazaki Y, Pfeilstocker M, Sekeres M, Sperr WR, Stauder R, Tauro S, Valent P, Vallespi T, van de Loosdrecht AA, Germing U, Haase D (2012) Revised international prognostic scoring system for myelodysplastic syndromes. Blood 120(12):2454-2465

5. Mufti GJ, Bennett JM, Goasguen J, Bain BJ, Baumann I, Brunning R, Cazzola M, Fenaux P, Germing U, Hellstrom-Lindberg E, Jinnai I, Manabe A, Matsuda A, Niemeyer CM, Sanz G, Tomonaga M, Vallespi T, Yoshimi A (2008) Diagnosis and classification of myelodysplastic syndrome: international working group on morphology of myelodysplastic syndrome (IWGM-MDS) consensus proposals for the definition and enumeration of myeloblasts and ring sideroblasts. Haematologica 93(11):1712-1717

6. Font P, Loscertales J, Soto C, Ricard P, Novas CM, Martin-Clavero E, Lopez-Rubio M, Garcia-Alonso L, Callejas M, Bermejo A, Benavente C, Ballesteros M, Cedena T, Calbacho M, Urbina R, Villarrubia J, Gil S, Bellon JM, Diez-Martin JL, Villegas A (2015) Interobserver variance in myelodysplastic syndromes with less than $5 \%$ bone marrow blasts: unilineage vs. multilineage dysplasia and reproducibility of the threshold of $2 \%$ blasts. Ann. Hematol. 94(4):565-573. https://doi.org/10.1007/ s00277-014-2252-4

7. Howe RB, Porwit-MacDonald A, Wanat R, Tehranchi R, Hellstrom-Lindberg E (2004) The WHO classification of MDS does make a difference. Blood 103(9):3265-3270. https://doi.org/ 10.1182/blood-2003-06-2124

8. Senent L, Arenillas L, Luno E, Ruiz JC, Sanz G, Florensa L (2013) Reproducibility of the World Health Organization 2008 criteria for myelodysplastic syndromes. Haematologica 98(4):568-575. https://doi.org/10.3324/haematol.2012.071449
9. Huang TC, Ko BS, Tang JL, Hsu C, Chen CY, Tsay W, Huang SY, Yao M, Chen YC, Shen MC, Wang CH, Tien HF (2008) Comparison of hypoplastic myelodysplastic syndrome (MDS) with normo-/hypercellular MDS by international prognostic scoring system, cytogenetic and genetic studies. Leukemia 22(3):544-550. https://doi.org/10.1038/sj.leu.2405076

10. Lambertenghi-Deliliers G, Orazi A, Luksch R, Annaloro C, Soligo D (1991) Myelodysplastic syndrome with increased marrow fibrosis: a distinct clinico-pathological entity. Br. J. Haematol. 78(2):161-166

11. Orazi A, Czader MB (2009) Myelodysplastic syndromes. Am. J. Clin. Pathol. 132(2):290-305. https://doi.org/10.1309/ AJCPRCXX4R0YHKWV

12. Fu B, Jaso JM, Sargent RL, Goswami M, Verstovsek S, Medeiros LJ, Wang SA (2014) Bone marrow fibrosis in patients with primary myelodysplastic syndromes has prognostic value using current therapies and new risk stratification systems. Mod Pathol 27(5):681689. https://doi.org/10.1038/modpathol.2013.187

13. Della Porta MG, Malcovati L, Boveri E, Travaglino E, Pietra D, Pascutto C, Passamonti F, Invernizzi R, Castello A, Magrini U, Lazzarino M, Cazzola M (2009) Clinical relevance of bone marrow fibrosis and CD34-positive cell clusters in primary myelodysplastic syndromes. J Clin Oncol 27(5):754-762

14. Xiong B, Nie Y, Tang Z, Xue M, Zuo X (2017) Prognostic evaluation of ALIP and CD34 immunostaining in IPSS-R subgroups of myelodysplastic syndromes. Pathology 49(5):526-533. https://doi. org/10.1016/j.pathol.2017.05.001

15. Malcovati L, Hellstrom-Lindberg E, Bowen D, Ades L, Cermak J, Del Canizo C, Della Porta MG, Fenaux P, Gattermann N, Germing U, Jansen JH, Mittelman M, Mufti G, Platzbecker U, Sanz GF, Selleslag D, Skov-Holm M, Stauder R, Symeonidis A, van de Loosdrecht AA, de Witte T, Cazzola M, European Leukemia N (2013) Diagnosis and treatment of primary myelodysplastic syndromes in adults: recommendations from the European LeukemiaNet. Blood 122(17):2943-2964. https://doi.org/10.1182/ blood-2013-03-492884

16. Arber DA, Orazi A, Hasserjian R, Thiele J, Borowitz MJ, Le Beau MM, Bloomfield CD, Cazzola M, Vardiman JW (2016) The 2016 revision to the World Health Organization classification of myeloid neoplasms and acute leukemia. Blood 127(20):2391-2405. https:// doi.org/10.1182/blood-2016-03-643544

17. Kern W, Haferlach C, Schnittger S, Haferlach T (2010) Clinical utility of multiparameter flow cytometry in the diagnosis of 1013 patients with suspected myelodysplastic syndrome: correlation to cytomorphology, cytogenetics, and clinical data. Cancer 116(19):4549-4563

18. Kern W, Haferlach C, Schnittger S, Alpermann T, Haferlach T (2013) Serial assessment of suspected myelodysplastic syndromes: significance of flow cytometric findings validated by cytomorphology, cytogenetics, and molecular genetics. Haematologica 98(2):201-207. https://doi.org/ 10.3324/haematol.2012.066787

19. Sandes AF, Kerbauy DM, Matarraz S, Chauffaille Mde L, Lopez A, Orfao A, Yamamoto M (2013) Combined flow cytometric assessment of CD45, HLA-DR, CD34, and CD117 expression is a useful approach for reliable quantification of blast cells in myelodysplastic syndromes. Cytometry B Clin Cytom 84(3):157-166. https://doi. org/10.1002/cyto.b.21087

20. Jelic TM, Mellen PF, Zavieh K, Roque JC, Farren SP, Jin B, Ahmad N, Estallila OC, Chang HH (2002) Correlation between the percentages of myeloblasts in bone marrow obtained by flow cytometry and manual counting on glass slide smears in 74 hematologic patients. Leuk Lymphoma 43(10):1927-1931. https://doi.org/10. 1080/1042819021000015871

21. Wells DA, Benesch M, Loken MR, Vallejo C, Myerson D, Leisenring WM, Deeg HJ (2003) Myeloid and monocytic dyspoiesis as determined by flow cytometric scoring in myelodysplastic syndrome correlates with the IPSS and with outcome after hematopoietic stem cell transplantation. Blood 102(1):394-403 
22. Loken MR, van de Loosdrecht A, Ogata K, Orfao A, Wells DA (2008) Flow cytometry in myelodysplastic syndromes: report from a working conference. Leuk Res 32(1):5-17. https://doi.org/10. 1016/j.leukres.2007.04.020

23. van de Loosdrecht AA, Alhan C, Bene MC, Della Porta MG, Drager AM, Feuillard J, Font P, Germing U, Haase D, Homburg $\mathrm{CH}$, Ireland R, Jansen JH, Kern W, Malcovati L, Te Marvelde JG, Mufti GJ, Ogata K, Orfao A, Ossenkoppele GJ, Porwit A, Preijers FW, Richards SJ, Schuurhuis GJ, Subira D, Valent P, van der Velden VH, Vyas P, Westra AH, de Witte TM, Wells DA, Loken MR, Westers TM (2009) Standardization of flow cytometry in myelodysplastic syndromes: report from the first European LeukemiaNet working conference on flow cytometry in myelodysplastic syndromes. Haematologica 94(8):1124-1134

24. Ogata K, Kishikawa Y, Satoh C, Tamura H, Dan K, Hayashi A (2006) Diagnostic application of flow cytometric characteristics of CD34+ cells in low-grade myelodysplastic syndromes. Blood 108(3):1037-1044. https://doi.org/10.1182/blood-2005-12-4916

25. Matarraz S, Lopez A, Barrena S, Fernandez C, Jensen E, FloresMontero J, Rasillo A, Sayagues JM, Sanchez ML, Barcena P, Hernandez-Rivas JM, Salvador C, Fernandez-Mosteirin N, Giralt M, Perdiguer L, Laranjeira P, Paiva A, Orfao A (2010) Bone marrow cells from myelodysplastic syndromes show altered immunophenotypic profiles that may contribute to the diagnosis and prognostic stratification of the disease: a pilot study on a series of 56 patients. Cytometry B Clin Cytom 78(3):154-168. https://doi. org/10.1002/cyto.b.20513

26. Font P, Subira D, Matarraz S, Benavente C, Cedena MT, Morado M, Perez Corral A, Bellon JM, Diez-Martin JL (2018) Multicenter comparison of CD34+ myeloid cell count by flow cytometry in low-risk myelodysplastic syndrome. Is it feasible? Cytometry B Clin Cytom 94(3):527-535. https://doi.org/10.1002/cyto.b.21538

27. Porwit A, van de Loosdrecht AA, Bettelheim P, Brodersen LE, Burbury K, Cremers E, Della Porta MG, Ireland R, Johansson U, Matarraz S, Ogata K, Orfao A, Preijers F, Psarra K, Subira D, Valent P, van der Velden VH, Wells D, Westers TM, Kern W, Bene MC (2014) Revisiting guidelines for integration of flow cytometry results in the WHO classification of myelodysplastic syndromesproposal from the International/European LeukemiaNet Working Group for Flow Cytometry in MDS. Leukemia 28(9):1793-1798. https://doi.org/10.1038/leu.2014.191

28. van de Loosdrecht AA, Westers TM, Ossenkoppele GJ (2008) Flowcytometry in myelodysplastic syndromes: towards a new paradigm in diagnosis and prognostication? LeukRes 32(2):205-207

29. van de Loosdrecht AA, Ireland R, Kern W, Della Porta MG, Alhan C, Balleisen JS, Bettelheim P, Bowen DT, Burbury K, Eidenschink L, Cazzola M, Chu SS, Cullen M, Cutler JA, Drager AM, Feuillard J, Fenaux P, Font P, Germing U, Haase D, Hellstrom-Lindberg E, Johansson U, Kordasti S, Loken MR, Malcovati L, te Marvelde JG, Matarraz S, Milne T, Moshaver B, Mufti GJ, Nikolova V, Ogata K, Oelschlaegel U, Orfao A, Ossenkoppele GJ, Porwit A, Platzbecker U, Preijers F, Psarra K, Richards SJ, Subira D, Seymour JF, Tindell V, Vallespi T, Valent P, van der Velden VH, Wells DA, de Witte TM, Zettl F, Bene MC, Westers TM (2013) Rationale for the clinical application of flow cytometry in patients with myelodysplastic syndromes: position paper of an international consortium and the European LeukemiaNet Working Group. Leuk Lymphoma 54(3): 472-475. https://doi.org/10.3109/10428194.2012.718341

30. Westers TM, Ireland R, Kern W, Alhan C, Balleisen JS, Bettelheim P, Burbury K, Cullen M, Cutler JA, Della Porta MG, Drager AM, Feuillard J, Font P, Germing U, Haase D, Johansson U, Kordasti S, Loken MR, Malcovati L, Te Marvelde JG, Matarraz S, Milne T, Moshaver B, Mufti GJ, Ogata K, Orfao A, Porwit A, Psarra K, Richards SJ, Subira D, Tindell V, Vallespi T, Valent P, van der Velden VH, de Witte TM, Wells DA, Zettl F, Bene MC, van de Loosdrecht AA (2012) Standardization of flow cytometry in myelodysplastic syndromes: a report from an international consortium and the European LeukemiaNet Working Group. Leukemia 26(7):1730-1741

31. Della Porta MG, Picone C, Pascutto C, Malcovati L, Tamura H, Handa H, Czader M, Freeman S, Vyas P, Porwit A, Saft L, Westers TM, Alhan C, Cali C, van de Loosdrecht AA, Ogata K (2012) Multicenter validation of a reproducible flow cytometric score for the diagnosis of low-grade myelodysplastic syndromes: results of a European LeukemiaNET study. Haematologica 97(8):1209-1217. https://doi.org/10.3324/haematol.2011.048421

32. Arber DA, Hasserjian RP (2015) Reclassifying myelodysplastic syndromes: what's where in the new WHO and why. Hematology Am Soc Hematol Educ Program 2015:294-298. https://doi.org/10. 1182/asheducation-2015.1.294

33. Thiele J, Kvasnicka HM, Facchetti F, Franco V, van der Walt J, Orazi A (2005) European consensus on grading bone marrow fibrosis and assessment of cellularity. Haematologica 90(8):11281132

34. Bjorklund E, Mazur J, Soderhall S, Porwit-MacDonald A (2003) Flow cytometric follow-up of minimal residual disease in bone marrow gives prognostic information in children with acute lymphoblastic leukemia. Leukemia 17(1):138-148

35. Malcovati L, Germing U, Kuendgen A, Della Porta MG, Pascutto C, Invernizzi R, Giagounidis A, Hildebrandt B, Bernasconi P, Knipp S, Strupp C, Lazzarino M, Aul C, Cazzola M (2007) Timedependent prognostic scoring system for predicting survival and leukemic evolution in myelodysplastic syndromes. J Clin Oncol 25(23):3503-3510

36. Stetler-Stevenson M, Arthur DC, Jabbour N, Xie XY, Molldrem J, Barrett AJ, Venzon D, Rick ME (2001) Diagnostic utility of flow cytometric immunophenotyping in myelodysplastic syndrome. Blood 98(4):979-987

37. Bellos F, Kern W (2017) Flow cytometry in the diagnosis of myelodysplastic syndromes and the value of myeloid nuclear differentiation antigen. Cytometry B Clin Cytom 92(3):200-206. https://doi.org/10.1002/cyto.b.21190

38. Dunphy CH, O'Malley DP, Perkins SL, Chang CC (2007) Analysis of immunohistochemical markers in bone marrow sections to evaluate for myelodysplastic syndromes and acute myeloid leukemias. Appl Immunohistochem Mol Morphol 15(2):154-159. https://doi. org/10.1097/PAI.0b013e318030dec7

39. Dunphy CH, Polski JM, Evans HL, Gardner LJ (2001) Evaluation of bone marrow specimens with acute myelogenous leukemia for CD34, CD15, CD117, and myeloperoxidase. Arch Pathol Lab Med 125(8):1063-1069. https://doi.org/10.1043/0003-9985(2001) 125<1063:EOBMSW>2.0.CO;2

40. Hanson CA, Ross CW, Schnitzer B (1992) Anti-CD34 immunoperoxidase staining in paraffin sections of acute leukemia: comparison with flow cytometric immunophenotyping. Hum Pathol 23(1):26-32. https://doi.org/10.1016/0046-8177(92) 90006-о

41. Manaloor EJ, Neiman RS, Heilman DK, Albitar M, Casey T, Vattuone T, Kotylo P, Orazi A (2000) Immunohistochemistry can be used to subtype acute myeloid leukemia in routinely processed bone marrow biopsy specimens. Comparison with flow cytometry. Am. J. Clin. Pathol. 113(6):814-822. https://doi.org/10.1309/nalm440g-4gfy-xpve

42. Torlakovic EE, Calvo KR, George TI, Hyjek E, Lee SH, Mazur J, Sabattini E, Saft L, Tzankov A, Porwit A (2018) Assessment of CD34-positive blasts in bone marrow core biopsy: inter-observer agreement study. Virchows Arch 473:S4-S4

Publisher's note Springer Nature remains neutral with regard to jurisdictional claims in published maps and institutional affiliations. 